\title{
Day warming, night warming, and the context dependency of trophic cascades
}

\author{
Cori Speights ${ }^{1}$ and Brandon Barton ${ }^{1}$ \\ ${ }^{1}$ Mississippi State University
}

May 14, 2020

\begin{abstract}
Inherent in climate change experiments is the assumption that researchers seek to understand the impacts of contemporary climate change and not the impacts of changes in the abiotic environment that are not predicted to occur. In general, climate warming is expected to be asymmetrical, with a mean increase in temperature that is driven more by warming at night rather than during the day. However, climate warming experiments tend to disproportionately increase daytime temperatures. If day and night warming have different effects on ecosystems, the mismatch in timing may produce misleading inference about the effects of climate change. To better understand how the timing of warming affects species and their interactions, we examined a food chain of lady beetles, aphids and host plants within environmental chambers programmed to simulate four w treatments (ambient, constant warming, day warming, and night warming). Our results show that the timing of warming influences predators and their interactions with prey in several ways. In plant-only treatments, all warming treatments increased plant above-ground biomass. When aphids were added, the positive direct effect of warming on plants disappeared, and night-warming indirectly reduced plant biomass more than the day- and constant-warming treatments. Although our feeding trial experiments found that lady beetles in day-warming treatments consumed the most aphids in a 24 hour period, predators generated a trophic cascade in only the night warming treatment. Our results contributes to mounting evidence predators can mediate the effects of climate warming and that these predators are affected by day and night warming differently.
\end{abstract}

\section{Introduction}

Predators have important impacts on ecosystems through direct effects on prey and indirect effects on the species that interact with the prey (Pace et al. 1999, Ripple et al. 2016) . The importance of top-down control in terrestrial systems has been debated (Wootton 1994, Shurin et al. 2002), and these arguments are complicated because the relative importance of top-down control may vary among experiments in different years even within the same systems and locations (e.g., Meserve et al. 2003, Noemi Mazia et al. 2004, Barton et al. 2009). Thus, while empirical studies often report different findings, synthesis across years and systems reveals that trophic cascades are context dependent and influenced by the abiotic environment (Chamberlain et al. 2014, Rosenblatt and Schmitz 2014). This is alarming, of course, because humans are rapidly altering Earth's environment in innumerable ways, and higher trophic levels are often the most sensitive to perturbations (Voigt et al. 2003, Ripple and Van Valkenburgh 2010). Thus, it is likely that the nature and strength of top-down control will continue to change in the Anthropocene.

Inherent in a climate change study is the assumption that researchers are interested in understanding the effects of contemporary climate change occurring on Earth, and less interested in understanding the effects of a climate change that is not expected to occur on our planet. Thus, given that species interactions are context dependent and that subtle changes in abiotic factors can influence outcomes, climate change studies must be as realistic as possible if they are to facilitate a predictive understanding of contemporary climate change. However, implementing realistic warming treatments, especially in the field, can be difficult because of logistical constraints (De Boeck et al. 2015). For example, electricity is not always available, 
and therefore warming treatments are often created with passive chambers that rely on solar energy to increase temperatures (Aronson and McNulty 2009). These designs tend to disproportionately warm during the day when solar energy is high, and they produce relatively little warming during the night (Speights et al. 2018). This is concerning because, on average, Earth's minimum temperatures are increasing at a faster rate than maximum temperatures (Easterling et al. 1997, Davy et al. 2017) and organisms are expected to respond differently to day and night warming (Speights and Barton 2019). Consequently, experiments that use unrealistic warming treatments may come to unrealistic conclusions and contribute to misleading predictions about the effects of climate change (Speights et al. 2017).

The impacts of diel asymmetries in warming on ecosystems is vastly understudied (Gaston 2019). Research comparing day and night warming has mostly focused on the direct effects of warming on plants (e.g., Peng et al. 2004, Bai et al. 2012, Fan et al. 2015, García et al. 2015, Loka and Oosterhuis 2015, Fu et al. 2016, Rossi and Isabel 2017). Fewer studies have investigated the effects of night warming on predators and their interactions with lower trophic levels. However, Barton and Schmitz (2018) demonstrated that spiders had different responses to day- and night-warming that resulted in opposite indirect effects on plant communities. Similarly, Speights and Barton (2019) showed that day and night warming can have different impacts on lady beetle development, predation, and respiration rates. Although these examples are limited, there is consistent evidence that the timing of warming matters and can dramatically influence conclusions.

We report here a comparison of the effects of constant, day, and night warming on a food chain comprising predatory lady beetles (Harmonia axyridis ); their prey, pea aphids (Acyrthosiphone pisum ); and fava bean (Vicia faba) host plants. These species have a proven record for testing other hypotheses about the top-down effects of warming (e.g., Harmon et al. 1998, Murrell and Barton 2017, Higashi et al. 2020). We hypothesized that the different timing of warming would alter the effects of warming on these species. Specifically, we expected day warming to increase top-down control by lady beetles. Studies have reported both positive and negative effects of day warming on pea aphid population growth rates (Harmon et al. 1998, Ryalls et al. 2013). However, in general, predation rates by lady beetles are expected to increase with warming (Barton and Ives 2014, Schwarz and Frank 2019) and therefore are likely to ameliorate any positive effects of day warming on aphid abundance. In contrast, we expected night warming to decrease top-down control by lady beetles. While night warming has been shown to increase pea aphid population growth rates (Miller et al. 2017), H. axyridis lady beetles rely on vision to find prey and therefore consume fewer aphids in low-light conditions (Harmon et al. 1998). Thus, darkness was expected to prevent $H$. axyridis lady beetles from increasing predation rates in night warming treatments, and therefore result in different effects of day and night warming on aphid abundance and plant biomass.

\section{Methods}

Pea aphids are phloem feeding insects that generally reproduce through through parthenogenesis (MacKay et al. 1993), allowing them to rapidly increase in population size and sometimes reach economically damaging densities on crops. Multicolored Asian Lady beetles are aphidaphagous predators that were introduced to North America numerous times as biological control agents (Koch 2003). These lady beetles have become an important part of agroecosystems, and their predation helps generate a trophic cascade that can benefit crops (Cardinale et al. 2003). The lady beetles and pea aphids used in this study were obtained from laboratory colonies maintained at Mississippi State University. The lady beetle colony was established with wild-caught individuals from locations near Starkville, MS and was supplemented each year to maintain genetic variation and natural phenotypes. Because pea aphids are parthenogenic, all aphids in the study were genetically identical clones (clonal line a2a; pink/red color). Aphid colonies were maintained on fava bean plants (Windsor variety; Johnny's Selected Seeds, Winslow, Maine, USA).

All experiments were conducted in plant growth chambers (Percival, Model: E41L2C8, Perry, Iowa, USA) at Mississippi State University in Spring 2018. The four temperature treatments were an "ambient" treatment with a 19 mean temperature $(14 / 24, \min / \max )$ and three warming treatments that each had 23 means, but differed in their minimum and maximum temperatures in the following ways: constant (18/28), day (14/32), and night warming (22/24) (for additional details see Table 4.1). For our methods, ambient represents a 
reference temperature commonly encountered by these insects. All growth chambers were programmed to maintain $40 \%$ relative humidity and a $12 / 12 \mathrm{~h}$ light/dark cycle.

To determine if temperature treatments had different effects on top-down control of aphid density and plant biomass, we conducted a $4 \times 3$ factorial experiment crossing temperature treatments (ambient, day, night, and constant warming) and trophic levels (plant $(\mathrm{P})$, plant + herbivore $(\mathrm{PH})$, and plant + herbivore + predator (PHP)). Four fava bean seeds were planted in 15 soil pots and placed into a growth chamber. Each pot was watered at least every other day throughout the duration of the experiment. After 14 days, we removed the weakest of the four plants, leaving three plants, and then covered the pot with a clear plastic cylinder (approximately $20 \mathrm{~cm} \mathrm{~d} \mathrm{x} 30 \mathrm{~cm} \mathrm{ht}$ ) and insect mesh top. Additionally, one mesh-covered opening $(5 \mathrm{~cm} \times 7 \mathrm{~cm})$ was installed into each cylinder to increase air flow.

Each pot was assigned to one of the three trophic-level treatments. Pots assigned to PH and PHP treatment pots received ten aphids per plant (30 aphids per pot). After six days of aphid population growth, we began acclimating lady beetles by placing them in petri dishes and randomly assigning them to growth chambers. On day seven, we counted the number of aphids in each pot to determine initial aphid abundance at the beginning of the experiment. Immediately afterwards, PHP treatments were stocked with one adult lady beetle per pot. One week later, lady beetles were removed and the number of aphids on each plant were counted. Plants were placed in paper bags and dried at 60deg C for 48 hours. After 48 hours, dried plants were weighed on an electronic balance (Mettler Toledo PL602-S).

We performed another experiment to determine if consumption of aphids by lady beetles differed due to temperature treatments. We placed lady beetles ( 8 individuals per block x 3 blocks for each of 4 temperature treatments) in an individual deli container inside a growth chamber set at one of the four temperature treatments. Lady beetles were fed aphids ad libitum daily. After a five-day acclimation period, lady beetles were given 50 aphids in 12-hour intervals (06:00-18:00 and 18:00-06:00). After each twelve-hour interval, the number of aphids were counted. Any remaining aphids were removed, and 50 new aphids were given to each lady beetle. This process continued for three days. Lady beetles were returned to the lab colony after the experiment. This process was replicated three times for each temperature treatment. One lady beetle in the ambient treatment did not survive the acclimation period, leaving 23 total lady beetles in that treatment. All other treatments produced data from 24 lady beetles.

Data were analyzed in the $\mathrm{R}$ statistical programing environment ( $\mathrm{R}$ Core Team 2016). We used a linear mixed-effects model to analyze aphid abundance and plant biomass. While count data are often Poisson distributed, this distribution can converge onto a normal distribution. Therefore, we compared a normal and Poisson model using the Akaike information criterion (AIC) estimator and selected the normally distributed model for further analyses. Warming type was a four-level (ambient, constant, day, or night) fixed effect and experimental block was used as a random effect. Post-hoc tests (least square means) for aphid abundance were separated and tested based on predator presence or absence. Post-hoc tests (least square means) for plant biomass were separated and tested based on trophic level (P, PH, and PHP).

We evaluated lady beetle predation rate using a general linear mixed-effects model with binomial error distribution. Time was a two-level (day or night) fixed effect, warming type was a four-level (ambient, constant, day, or night) fixed effect and experimental block was used as a random effect. A separate model was generated to compare lady beetle predation throughout the 24-hour day. For the 24-hour model warming type was a four-level (ambient, constant, day, or night) fixed effect and experimental block was used as a random effect. Inferences from the models are based on likelihood ratio tests comparing models with and without the specific predictor variables (e.g., temperature treatment and time of day). Post-hoc tests (least square means) for proportion of aphids consumed were tested to determine treatment level differences.

\section{Results}

\section{Plant Biomass}

We did not detect an interaction between warming treatment and trophic level $(\mathrm{df}=6$, Chisq $=7.98, \mathrm{p}$ 
$=0.24)$ on above-ground plant biomass, although there were main effects of warming treatment $(\mathrm{df}=3$, Chisq $=16.18, \mathrm{p}=0.001 ;$ Figure 1$)$ and trophic level treatment $(\mathrm{df}=2$, Chisq $=27.88, \mathrm{p}<0.001)$. In the absence of an herbivore and predator, plant biomass was significantly larger in constant- $(1.03+-0.05 \mathrm{~g}, \mathrm{p}$ $=0.048)$, day- $(1.05+-0.06 \mathrm{~g}, \mathrm{p}=0.029)$, and night-warming treatments $(1.09+-0.06 \mathrm{~g}, \mathrm{p}=0.007)$ relative to the ambient treatment $(0.79+-0.05 \mathrm{~g})$. In the absence of a predator there was not a significant effect of warming treatment on plant above-ground biomass $(\mathrm{df}=3$, Chisq $=5.45, \mathrm{p}=0.14)$. When all three trophic levels were present, warming treatment tended to have an effect on above-ground plant biomass (df $=3$, Chisq $=6.57, \mathrm{p}=0.087)$, with an increase in the night-warming treatment $(0.92+-0.09 \mathrm{~g})$ compared to ambient $(0.65+-0.04 \mathrm{~g})$, constant $(0.73+-0.11 \mathrm{~g})$, and day-warming treatments $(0.66+-0.08 \mathrm{~g})$.

\section{Aphid Abundances}

The interaction between predator presence and warming treatment on aphid abundances trended toward significance $(\mathrm{df}=3$, Chisq $=6.78, \mathrm{p}=0.079$; Figure 2$)$, and there were also individual effects of warming treatment $(\mathrm{df}=3$, Chisq $=56.26, \mathrm{p}<0.001 ;$ Figure 1$)$ and predator presence $(\mathrm{df}=1$, Chisq $=11.06, \mathrm{p}<$ $0.001)$. In the absence of predators, warming affected aphid abundance ( $\mathrm{df}=3$, Chisq $=39.22, \mathrm{p}<0.001)$. Specifically, there were fewer aphids in the ambient treatment compared to all other warming treatments (all p's $<0.01$ ). There was not a difference between the constant treatment and day or night treatments (all p's $>0.1$ ), although there was a higher abundance of aphids in the night-warming treatment compared to the day-warming treatment $(\mathrm{p}=0.0071)$. In the presence of predators, warming had an effect on aphid abundance $(\mathrm{df}=3$, Chisq $=21.44, \mathrm{p}<0.001)$. Specifically, there were fewer aphids in the ambient treatment compared to all other warming treatments (all p's $<0.01$ ). There were no differences between any of the warming treatments (all p's $=0.9$ ).

\section{Predation Rate}

Aphid consumption by lady beetles was significantly impacted by the interaction of warming treatment and time of day (day vs. night; $\mathrm{df}=3$, Chisq $=209.76, \mathrm{p}<0.0001$; Figure 3 ). Lady beetles in day-warming treatments consumed the most aphids during the day (06:00-18:00; all p's $<0.01)$, and night-warming treatments consumed the most aphids during the night (18:00-06:00; all p's $<0.01)$. When the data were combined to represent total aphids eaten throughout a 24-hour period, there was a significant effect of warming treatment on consumption $(\mathrm{df}=3$, Chisq $=402.76, \mathrm{p}<0.0001)$. All warming treatments increased lady beetle consumption relative to the ambient treatment (all p's $<0.01$ ).

\section{Discussion}

Our results corroborate previous studies that show climate warming can influence top-down control of herbivores and plants by predators. Our research also contributes to a growing appreciation for the context dependency of warming and demonstrates that the timing of warming can mediate the net effect on a community. Specifically, this study found different results for night warming compared to day and constant warming. We detected evidence of a trophic cascade in night warming treatments that was not apparent in day- or constant-warming treatments. These results shed light on the effects of asymmetrical warming, an underappreciated nuance in environmental change, and the potential consequences of its absence in climate change studies.

In the absence of predators and herbivores (P treatment), we found that all warming treatments had a positive direct effect on above-ground plant biomass. This result is not shocking, as climate warming commonly increases plant biomass (Lin et al. 2010). However, when aphids were added (PH treatment) the positive direct effect of warming on plants was negated. Aphids reduced plant biomass in all warming treatments relative to the biomass of plants grown without aphids. Night-warming plant biomass decreased at a higher magnitude compared to constant- and day-warming treatments. This effect could be attributed to constant- and day-warming having a moderately positive effect on aphids that increased their abundance approximately three times higher than that found in ambient treatments (Figure 2). However, in the night-warming treatments, aphids benefited significantly more and reached the highest abundances of any treatment, approximately 1.5 times as high as the other warming treatments and four times larger than 
ambient treatments. As such, the positive direct effect of night warming on plant biomass disappeared; aphids suppressed final plant biomass so that ambient- and night-warming treatments did not differ. Such different responses of aphids to day and night warming are not unexpected. For example, night warming has been shown to increase pea aphid abundances (Miller et al. 2017) whereas increased day temperatures can cause heat stress that reduces reproduction rates (Harmon et al. 2009).

The presence of a predator (PHP treatment) reduced aphid abundances in all temperature treatments except day warming (relative to PH treatment) and all warming treatments had higher final aphid abundances than the ambient (Figure 2). When predators were present, the final aphid density did not differ among the three warming treatments. This result is somewhat consistent with data from the predation rate experiment. That is, lady beetles increased predation rates when warmed, with day-warmed beetles consuming the most aphids during the day and night-warmed beetles consuming the most aphids at night (Figure 3). Inexplicably, the total consumption over 24 hours differed among all warming treatments, yet aphids still reached similar abundances in the tritrophic experiment. Such inconsistencies suggest that there are subtle effects of warming within the tritrophic system that are beyond the scope of this study.

Despite the predators in day-warming treatments consuming the most aphids in the foraging experiment, we only detected a trophic cascade with night warming (Figure 1). The mechanisms driving the lack of a trophic cascade in day-warming treatments is unknown but not unprecedented. For example, Flynn et al. (2006) studied the effects of aphids on plant biomass and only documented a reduction in plant biomass in their highest warming treatment, despite similar aphid densities in ambient and warmed treatments. They hypothesized this outcome could be a result of increased aphid development rate or decreased aphid metabolic efficiency. Nonetheless, both Flynn et al. (2006) and our study supports the result that similar aphid population sizes can have different effects on plant biomass.

The importance of trophic cascades has been studied for decades, yet we are still learning how this and many other processes will be impacted by future environmental change. This study provides for a unique investigation of top-down control in different climate warming scenarios. As reported with other species (Barton and Schimtz 2018), we show that night warming and day warming produced completely different indirect effects that cascade through the system. These results are alarming because they demonstrate that inference made from experiments that used warming treatments that are inconsistent with expected patterns of warming can be misleading. Therefore, we urge ecologists to think carefully about the realism of their climate manipulations and the implications of drawing conclusions from unrealistic warming treatments.

\section{Data availability statement}

Data collected and used in this manuscript will be made publicly available on Dryad.

\section{References}

Aronson, E. L., and S. G. McNulty. 2009. Appropriate experimental ecosystem warming methods by ecosystem, objective, and practicality. Agricultural and Forest Meteorology 149 :1791-1799.

Bai, W., J. Xia, S. Wan, W. Zhang, and L. Li. 2012. Day and night warming have different effect on root lifespan. Biogeosciences9 :375-384.

Barton, B. T., A. P. Beckerman, and O. J. Schmitz. 2009. Climate warming strengthens indirect interactions in an old-field food web. Ecology $90: 2346-2351$.

Barton, B. T., and A. R. Ives. 2014. Direct and indirect effects of warming on aphids, their predators, and ant mutualists. Ecology $95: 1479-1484$.

Barton, B. T., and O. J. Schmitz. 2018. Opposite effects of daytime and nighttime warming on top-down control of plant diversity. Ecology 99 :13-20.

Cardinale, B. J., C. T. Harvey, K. Gross, and A. R. Ives. 2003. Biodiversity and biocontrol: emergent impacts of a multi-enemy assemblage on pest suppression and crop yield in an agroecosystem. Ecology 
Letters 6 :857-865.

Chamberlain, S. A., J. L. Bronstein, and J. A. Rudgers. 2014. How context dependent are species interactions? Ecology Letters17:881-890.

Davy, R., I. Esau, A. Chernokulsky, S. Outten, and S. Zilitinkevich. 2017. Diurnal asymmetry to the observed global warming. International Journal of Climatology 37 :79-93.

De Boeck, H. J., S. Vicca, J. Roy, I. Nijs, A. Milcu, J. Kreyling, A. Jentsch, A. Chabbi, M. Campioli, and T. Callaghan. 2015. Global change experiments: challenges and opportunities. Bioscience65 :922-931.

Easterling, D. R., B. Horton, P. D. Jones, T. C. Peterson, T. R. Karl, D. E. Parker, M. J. Salinger, V. Razuvayev, N. Plummer, and P. Jamason. 1997. Maximum and minimum temperature trends for the globe. Science277:364-367.

Fan, Y., M. Tian, Q. Jing, Z. Tian, H. Han, D. Jiang, W. Cao, and T. Dai. 2015. Winter night warming improves pre-anthesis crop growth and post-anthesis photosynthesis involved in grain yield of winter wheat (Triticum aestivum L.). Field Crops Research $178: 100-108$.

Flynn, D. F., E. A. Sudderth, and F. Bazzaz. 2006. Effects of aphid herbivory on biomass and leaf-level physiology of Solanum dulcamara under elevated temperature and CO2. Environmental and Experimental Botany $56: 10-18$.

Fu, Y. H., Y. Liu, H. J. De Boeck, A. Menzel, I. Nijs, M. Peaucelle, J. Penuelas, S. Piao, and I. A. Janssens. 2016. Three times greater weight of daytime than of night-time temperature on leaf unfolding phenology in temperate trees. New Phytologist $212: 590-597$.

Garcia, G. A., M. F. Dreccer, D. J. Miralles, and R. A. Serrago. 2015. High night temperatures during grain number determination reduce wheat and barley grain yield: a field study. Global Change Biology21 :4153-4164.

Gaston, K. J. 2019. Nighttime Ecology: The "Nocturnal Problem" Revisited. The American Naturalist 193 :000-000.

Harmon, J. P., J. E. Losey, and A. Ives. 1998. The role of vision and color in the close proximity foraging behavior of four coccinellid species. Oecologia $115: 287-292$.

Harmon, J. P., N. A. Moran, and A. R. Ives. 2009. Species response to environmental change: impacts of food web interactions and evolution. Science $323: 1347-1350$.

Higashi, C.H.V., B.T. Barton, and K.M. Oliver. 2020. Warmer nights offer no respite for a defensive mutualism. Journal of Animal Ecology. https://doi.org/10.1111/1365-2656.13238

Koch, R. 2003. The multicolored Asian lady beetle, Harmonia axyridis: a review of its biology, uses in biological control, and non-target impacts. Journal of Insect Science 3 .

Leemans, R., and B. Eickhout. 2004. Another reason for concern: regional and global impacts on ecosystems for different levels of climate change. Global environmental change 14 :219-228.

Lin, D., J. Xia, and S. Wan. 2010. Climate warming and biomass accumulation of terrestrial plants: a meta-analysis. New Phytologist188 :187-198.

Loka, D. A., and D. M. Oosterhuis. 2015. Effects of high night temperatures on cotton leaf gas exchange and ATP levels at flowering. American Journal of Experimental Agriculture $8: 99-106$.

MacKay, P. A., R. J. Lamb, and M. A. Smith. 1993. Variability in life history traits of the aphid, Acyrthosiphon pisum (Harris), from sexual and asexual populations. Oecologia 94 :330-338.

Meserve, P. L., D. A. Kelt, W. B. Milstead, and J. R. Gutierrez. 2003. Thirteen years of shifting top-down and bottom-up control. Bioscience53 :633-646. 
Miller, C. R., B. T. Barton, L. Zhu, V. C. Radeloff, K. M. Oliver, J. P. Harmon, and A. R. Ives. 2017. Combined effects of night warming and light pollution on predator-prey interactions. Proc. R. Soc. B284 :20171195.

Murrell, E.G. and B.T. Barton. 2017. Warming alters prey density and biological control in conventional and organic agricultural systems. Integrative and comparative biology. 57:1-13.

Noemi Mazia, C., T. Kitzberger, and E. J. Chaneton. 2004. Interannual changes in folivory and bird insectivory along a natural productivity gradient in northern Patagonian forests. Ecography 27 :29-40.

Pace, M.L., J.J. Cole, S.R. Carpenter, J.F. Kitchell. 1999. Trophic cascades revealed in diverse ecosystems. Trends in ecology \& evolution 14: 483-488.

Peng, S., J. Huang, J. E. Sheehy, R. C. Laza, R. M. Visperas, X. Zhong, G. S. Centeno, G. S. Khush, and K. G. Cassman. 2004. Rice yields decline with higher night temperature from global warming. Proceedings of the National Academy of Sciences $101: 9971-9975$.

R Core Team. 2016. R: a language and environment for statistical computing. R Foundation for Statistical Computing, Vienna, Austria.

Ripple, W.J., J.A. Estes, O.J. Schmitz, V. Constant, M.J. Kaylor, A. Lenz, J.L. Motley, K.E. Self, D.S. Taylor and C. Wolf. 2016. What is a trophic cascade?. Trends in Ecology \& Evolution, 31:842-849.

Ripple, W. J., and B. Van Valkenburgh. 2010. Linking top-down forces to the Pleistocene megafaunal extinctions. Bioscience 60 :516-526.

Rosenblatt, A. E., and O. J. Schmitz. 2014. Interactive effects of multiple climate change variables on trophic interactions: a meta-analysis. Climate Change Responses $1: 8$.

Rossi, S., and N. Isabel. 2017. Bud break responds more strongly to daytime than night-time temperature under asymmetric experimental warming. Global Change Biology 23 :446-454.

Ryalls, J. M. W., M. Riegler, B. D. Moore, G. Lopaticki, and S. N. J. Johnson. 2013. Effects of elevated temperature and $\mathrm{CO} 2$ on aboveground-belowground systems: a case study with plants, their mutualistic bacteria and root/shoot herbivores. Frontiers in plant science $4: 445$.

Schwarz, T., and T. Frank. 2019. Aphid feeding by lady beetles: higher consumption at higher temperature. BioControl 64 :323-332.

Shurin, J. B., E. T. Borer, E. W. Seabloom, K. Anderson, C. A. Blanchette, B. Broitman, S. D. Cooper, and B. S. Halpern. 2002. A cross-ecosystem comparison of the strength of trophic cascades. Ecology Letters $\mathbf{5}$ :785-791.

Speights, C. J., and B. T. Barton. 2019. Timing is everything: Effects of day and night warming on predator functional traits. Food Webs21 :e00130.

Speights, C. J., J. P. Harmon, and B. T. Barton. 2017. Contrasting the potential effects of daytime versus nighttime warming on insects. Current Opinion in Insect Science.

Voigt, W., J. Perner, A. J. Davis, T. Eggers, J. Schumacher, R. Bahrmann, B. Fabian, W. Heinrich, G. Kohler, and D. Lichter. 2003. Trophic levels are differentially sensitive to climate. Ecology84:2444-2453.

Wootton, J. T. 1994. The nature and consequences of indirect effects in ecological communities. Annual Review of Ecology and Systematics25 :443-466.

Table 1. Daily temperature ranges $(\operatorname{deg} C)$ for each of the four temperature regimes.

\begin{tabular}{lll}
\hline Treatment & Time & Temperature \\
\hline Ambient & 0 & 14
\end{tabular}




\begin{tabular}{lll}
\hline Treatment & Time & Temperature \\
\hline Ambient & 600 & 19 \\
Ambient & 1200 & 24 \\
Ambient & 1800 & 19 \\
Constant & 0 & 18 \\
Constant & 600 & 23 \\
Constant & 1200 & 28 \\
Constant & 1800 & 23 \\
Day & 0 & 14 \\
Day & 600 & 23 \\
Day & 1200 & 32 \\
Day & 1800 & 23 \\
Night & 0 & 22 \\
Night & 600 & 23 \\
Night & 1200 & 24 \\
Night & 1800 & 23 \\
\hline
\end{tabular}

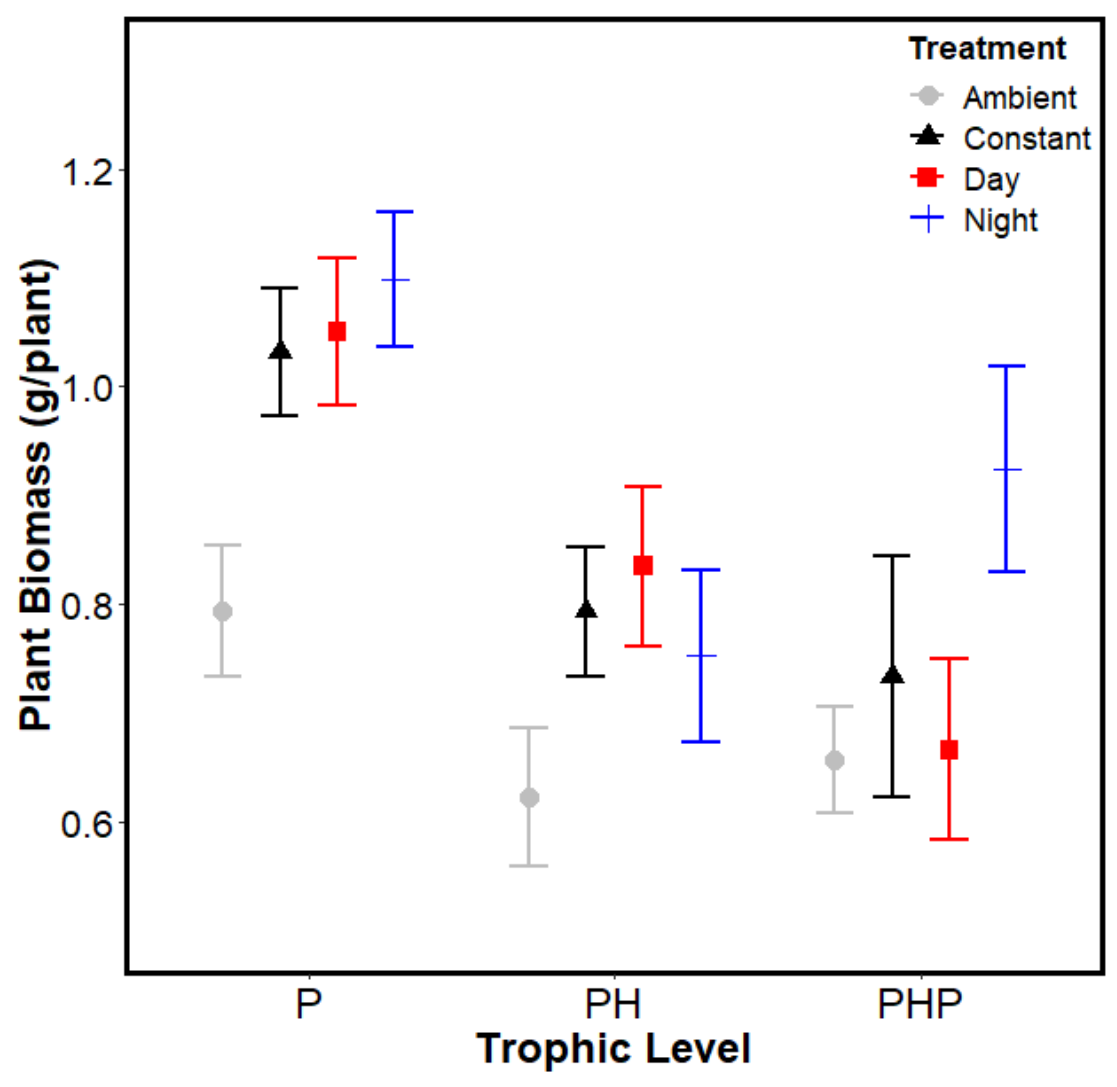

Figure 1. Plant above-ground biomass for each trophic level (plant $(\mathrm{P})$, plant + herbivore $(\mathrm{PH})$, and plant + herbivore + predator $(\mathrm{PHP})$ ) and temperature treatment. In $\mathrm{P}$ treatments, all warming types increased plant biomass. In $\mathrm{PH}$ treatments, all warming types decreased plant biomass with the largest reduction occurring in night-warming conditions. In PHP treatments, only night-warming conditions showed a trophic 
cascade by increasing plant biomass relative to $\mathrm{PH}$ treatments. Each point represents the mean value with standard error bars.

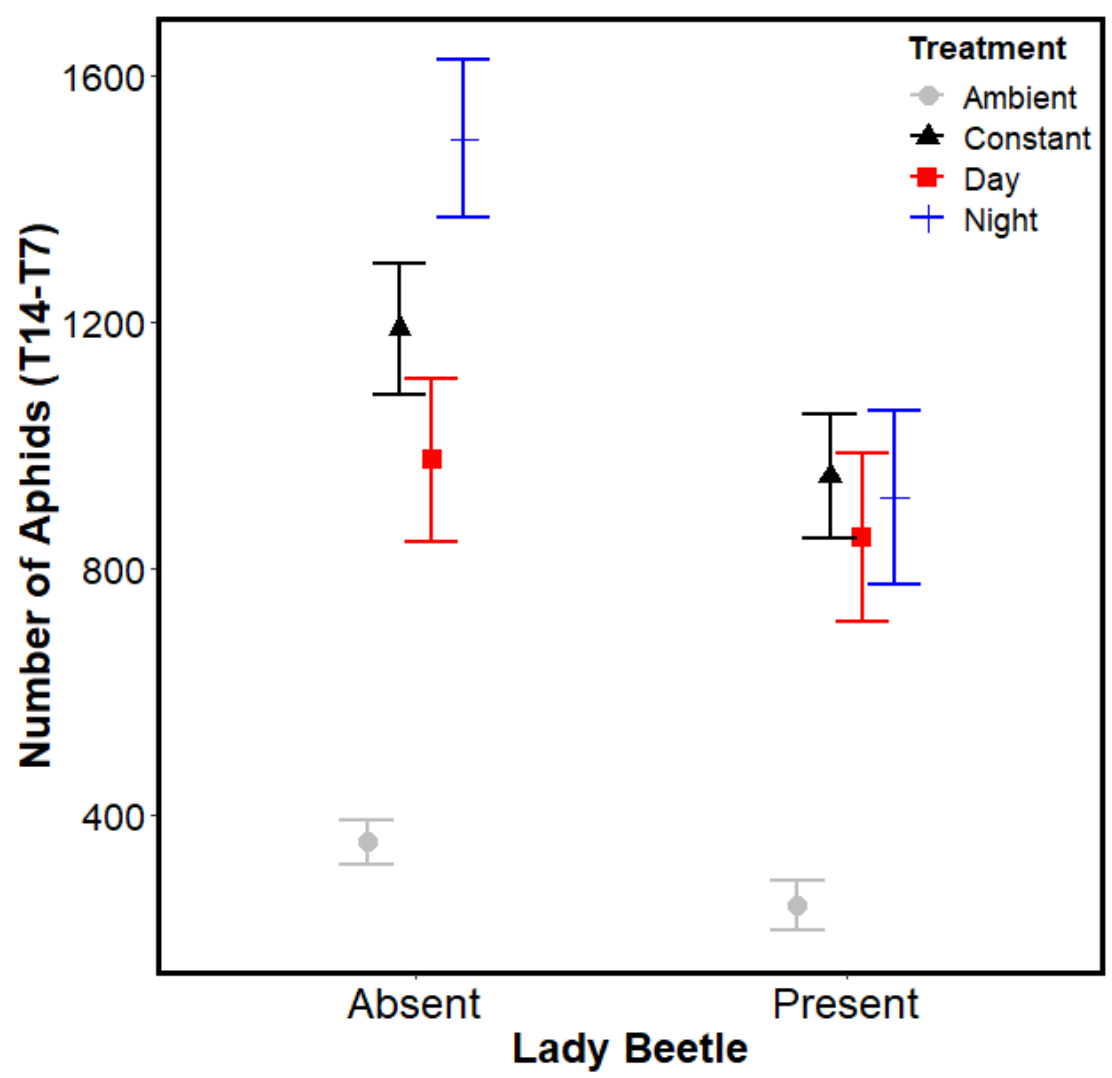

Figure 2. Number of pea aphids on three plants after one week in the presence or absence of lady beetle predators in four different temperature treatments. All warming treatments increased aphid abundances, but no differences were seen between warming treatments when lady beetles were present. Each point represents the mean value with standard error bars. 


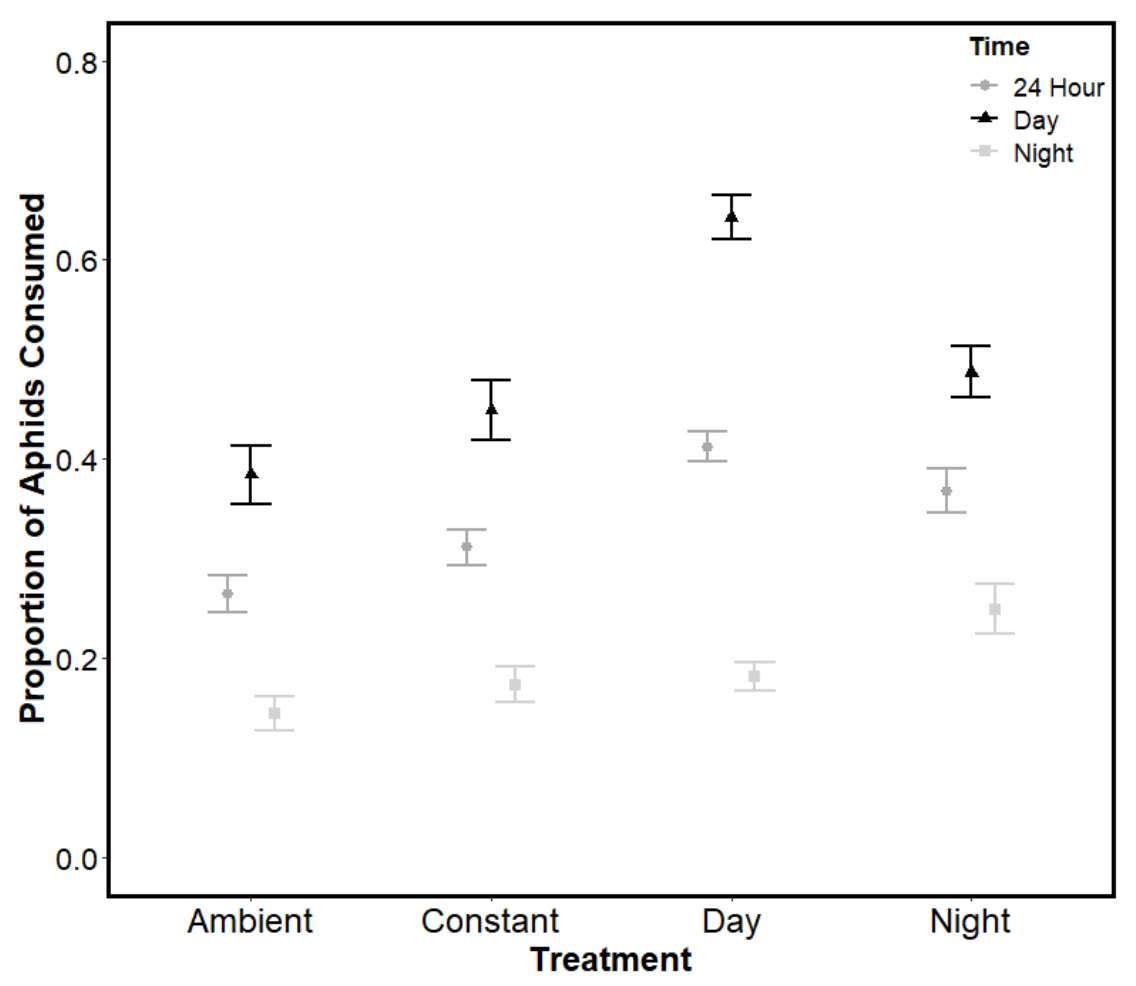

Figure 3. Proportion of aphids consumed (out of 50 for day and night and 100 for 24 hour) for lady beetles that had been acclimated to a temperature treatment for 5 days. Day-warming beetles consumed the most during day and night-warming beetles consumed the most during the night. Each point represents the mean value with standard error bars. 